\begin{tabular}{|c|c|c|c|}
\hline C. Roberto Simons-Linares, MD & Praneet Wander, MD & John Vargo, MD & Prabhleen Chahal, MD \\
\hline $\begin{array}{l}\text { Department of Gastroenterology, Hepatology, } \\
\text { and Nutrition, Cleveland Clinic }\end{array}$ & $\begin{array}{l}\text { Department of Gastroenterology, } \\
\text { Hofstra Northwell School of Medicine, } \\
\text { Hempstead, NY }\end{array}$ & $\begin{array}{l}\text { Medical Director of Advanced Endoscopy, } \\
\text { Department of Gastroenterology, Hepatology, } \\
\text { and Nutrition, Cleveland Clinic; Associate } \\
\text { Professor, Cleveland Clinic Lerner College of } \\
\text { Medicine of Case Western Reserve University, } \\
\text { Cleveland, OH }\end{array}$ & $\begin{array}{l}\text { Department of Gastroenterology, Hepatology, } \\
\text { and Nutrition, Cleveland Clinic; Clinical } \\
\text { Assistant Professor, Cleveland Clinic Lerner } \\
\text { College of Medicine of Case Western Reserve } \\
\text { University, Cleveland, OH }\end{array}$ \\
\hline
\end{tabular}

\title{
Endoscopic ultrasonography: An inside view
}

\section{ABSTRACT}

Endoscopic ultrasonography (EUS) has been used since the mid-1980s. Initially a diagnostic tool, it has since evolved into a therapeutic, minimally invasive surgical tool with significant impact on the diagnosis and management of a range of benign and malignant conditions. The authors review current indications, safety, and efficacy of EUS for diseases of the upper and lower gastrointestinal tract, posterior mediastinum, pancreas, bile duct, gallbladder, retroperitoneum, liver, adrenal glands, and kidneys.

\section{KEY POINTS}

EUS is commonly used in the diagnosis and management of biliary and pancreatic diseases, including guidance of biliary drainage in bile duct or pancreatic duct obstruction.

EUS-guided fine-needle aspiration aids staging of malignancies of the upper and lower digestive tract.

EUS is now increasingly used to drain abdominal fluid collections of nonpancreatic etiology.
TDOscopic ultrasonography (EUS) has evolved from a diagnostic tool to a therapeutic procedure for a wide range of conditions of the upper and lower gastrointestinal tract, hepatobiliary system, pancreas, adrenal glands, kidneys, retroperitoneum, and lymph nodes around the gastrointestinal tract. It can help differentiate benign from malignant disease and in many cases is an alternative to surgery.

This review of current and evolving diagnostic and therapeutic indications for EUS will help physicians identify patients who may benefit from this procedure.

\section{EUS VS OTHER IMAGING TESTS}

EUS offers advantages over other imaging tests. It does not involve radiation as in computed tomography (CT) or positron emission tomography, and it is not subject to the contraindications of magnetic resonance imaging (MRI) such as metal implants or claustrophobia. EUS offers high-resolution real-time imaging and can be combined with Doppler to evaluate vasculature and perform diagnostic procedures, angiotherapy, fine-needle aspiration biopsy, and core biopsy for tissue diagnosis. In addition, EUS allows therapeutic interventions. ${ }^{1}$

\section{PROCEDURAL REQUIREMENTS FOR THE PATIENT}

EUS is an outpatient procedure that usually takes 30 to 60 minutes and can be done under moderate sedation or general anesthesia.

\section{Periprocedural considerations}

According to guidelines of the American Society for Gastrointestinal Endoscopy (ASGE), ${ }^{2}$ patients fast for 8 hours before the procedure. 
For patients taking antithrombotics, guidelines recommend a platelet level greater than $50 \times 10^{9} / \mathrm{L}$ and an international normalized ratio below 1.5.

\section{The endoscope}

EUS is performed with a flexible wide endoscope with a small ultrasound probe and camera at the tip; other equipment in the scope depend on the indication and can include a fine-aspiration needle, a core biopsy needle, a celiac plexus blockade and neurolysis needle, and a metal or plastic stent. EUS can be performed using either a radial $\left(360^{\circ}\right)$ or a linear (approximately $120^{\circ}$ ) view. A narrow angle of view is required to allow endoscopic fineneedle aspiration.

\section{Expanding indications}

The indications for EUS are rapidly expanding. Uses identified by the American Cancer Society and the ASGE now include evaluation and staging of upper gastrointestinal malignancies, mediastinal adenopathy, pancreatic lesions and cancers, submucosal tumors, rectal cancer, and lung cancer staging. ${ }^{3}$ In particular, EUS has changed the approach to diagnosis and management of biliary and pancreatic diseases.

fine-needle aspiration improves diagnostic accuracy for pancreatic masses

\section{PANCREATIC DISORDERS}

\section{Pancreatic cancer}

Pancreatic cancer has a poor prognosis since it is usually diagnosed at an advanced stage. According to the American Cancer Society, the 1 -year relative survival rate is $20 \%$, and the 5 -year rate is $8 \%$ for all stages of pancreatic cancer. Current studies show that EUS has a sensitivity of $90 \%$ to $95 \%$ for detecting malignant pancreatic tumors measuring $2 \mathrm{~cm}$ to $3 \mathrm{~cm}$, which is far superior to other imaging modalities. ${ }^{4}$ EUS is considered complementary to CT or MRI for diagnosis and staging of pancreatic adenocarcinoma. EUS is also used to rule out pancreatic cancer if results of CT or MRI are ambiguous.

EUS in combination with fine-needle aspiration biopsy improves diagnostic accuracy for pancreatic masses and helps in histologic confirmation. ${ }^{5}$ Immediate cytologic evaluation or rapid on-site cytologic evaluation helps improve the yield.
The sensitivity of EUS declines in the setting of severe underlying chronic pancreatitis or severe acute pancreatitis. The challenges of detecting pancreatic malignancy in the setting of chronic pancreatitis are being addressed with the advent of EUS elastography, which evaluates tissue stiffness and helps with characterization of the lesion. ${ }^{6}$

\section{Acute pancreatitis}

Gallstones are the most common cause of acute pancreatitis. EUS has higher sensitivity than ultrasonography, CT, and magnetic resonance cholangiopancreatography in detecting common bile duct stones and sludge in patients with acute pancreatitis or recurrent pancreatitis.?

The ASGE recommends EUS for the assessment of choledocholithiasis in patients at intermediate risk. If EUS confirms bile duct stones, therapeutic endoscopic retrograde cholangiopancreatography (ERCP) can be performed with the patient under the same sedation; and if a stone is not present, an additional diagnostic procedure can be avoided. ${ }^{2}$

EUS also helps determine other causes of acute pancreatitis such as pancreas divisum, small pancreatic tumors undetected on CT or MRI, autoimmune pancreatitis, and chronic pancreatitis, and it can be an important investigative test in patients with idiopathic pancreatitis. $^{8}$

\section{Pancreatic fluid collections}

The revised Atlanta classification categorizes pancreatic fluid collections according to 4 types ${ }^{9}$ :

- Acute peripancreatic fluid collection, occurring in interstitial edematous pancreatitis

- Pancreatic pseudocyst, occurring as a delayed complication ( $>4$ weeks) of interstitial edematous pancreatitis

- Acute necrotic collection, occurring in necrotizing pancreatitis

- Walled-off necrosis, which has a radiologically identifiable capsule ( $>4$ weeks).

Surgical and percutaneous approaches have traditionally been used to drain symptomatic pancreatic and peripancreatic fluid collections. ${ }^{10}$ However, disadvantages of these procedures include higher cost, longer hospital stay, possibly higher morbidity risk, and 
discomfort of external catheters requiring multiple exchanges.

In the past few years, EUS-guided transgastric or transduodenal drainage has been used more frequently with comparable success and lower morbidity and costs than surgical and percutaneous drainage. The procedure is feasible in more than $90 \%$ of patients, is minimally invasive, and results in shorter hospital stays than surgical drainage, and compared with CT or MRI, it more accurately differentiates pseudocyst from cystic neoplasms. ${ }^{11}$

Complications of endoscopic drainage of pancreatic fluid collections are minimal and include bleeding, perforation, and infection, all with rates of less than $5 \% .^{12}$

\section{Chronic pancreatitis}

Chronic pancreatitis is a complex disease with an ill-defined epidemiology but significant rates of morbidity and mortality. Smoking and alcohol consumption are main risk factors. Chronic abdominal pain is the most common presentation.

Diagnosis can be challenging in early, mild, or moderate disease. Studies ${ }^{13-16}$ have shown that the diagnostic accuracy of EUS is comparable to that of ERCP and pancreatic function testing. In addition, technologic advances in EUS such as contrast-enhanced harmonics and elastography offer improved diagnostic accuracy in patients with chronic pancreatitis. ${ }^{17,18}$ As a result, EUS is being increasingly used as a frontline test for this indication.

\section{Pancreatic cystic neoplasms}

The challenge in management of pancreatic cystic neoplasms lies in the timely and accurate diagnosis of premalignant mucinous cysts.

Differentiation of premalignant mucinous cysts from benign nonmucinous cysts by EUS with fine-needle fluid aspiration has become a valuable tool, providing high-quality imaging of the cyst and samples for fluid analysis, leading to increased diagnostic accuracy.

Periprocedural antibiotics are administered to minimize the risk of infection from fine-needle aspiration. Cyst fluid samples are sent to the laboratory for cytologic study and for analysis for carcinoembryonic antigen, glucose, amylase, and mucin. ${ }^{19,20}$ Premalignant mucinous cysts are managed according to the international consensus guidelines. ${ }^{21,22}$

\section{GALLBLADDER AND BILIARY DISORDERS}

\section{Choledocholithiasis}

Common bile duct stones can be present in $20 \%$ of patients with cholelithiasis. Noninvasive imaging with abdominal ultrasonography or CT has a diagnostic accuracy of only $50 \%$ for these stones. Magnetic resonance cholangiopancreatography is the most accurate noninvasive imaging test (diagnostic accuracy from $81 \%$ to $99 \%) .{ }^{23-26}$

ERCP and intraoperative cholangiography are accurate but invasive and can cause complications. Same-session EUS and ERCP (if stones are confirmed on EUS) for common bile duct stones are usually performed in patients with intermediate probability of stones according to the ASGE criteria or in patients with contraindications to magnetic resonance cholangiopancreatography.

\section{Obstructive jaundice}

Obstructive jaundice can result from benign and malignant diseases. Common benign causes are choledocholithiasis, postcholecystectomy bile duct injury, liver transplant, portal cavernoma cholangiopathy, primary sclerosing cholangitis, acquired immunodeficiency syndrome cholangiopathy, chronic pancreatitis, and immunoglobulin G4 cholangiopathy. Malignant causes include cholangiocarcinoma, gallbladder carcinoma, pancreatic malignancies, ampullary carcinoma, metastasis, metastatic lymph nodal compression on bile duct, and hepatocellular carcinoma. The proximity of the stomach and duodenum to the extrahepatic biliary system makes EUS useful for imaging the biliary anatomy. EUS-guided fine-needle aspiration from the bile duct wall and surrounding lymph nodes enables histologic diagnosis.

ERCP is the standard procedure for biliary drainage in benign or malignant biliary obstruction. However, it is not feasible in surgically altered anatomy as in Roux-en-Y anastomosis and duodenal bulb infiltration by tumor. In these cases, EUS-guided biliary drainage is being used with high success rates. ${ }^{27,28}$ EUSguided cholangiopancreatography has been done in patients in whom ERCP could not be performed. This procedure requires a high level of technical expertise and can cause complications such as perforation and bile leak.

\section{EUS is routinely used for diagnosis and staging of malignant esophageal tumors}




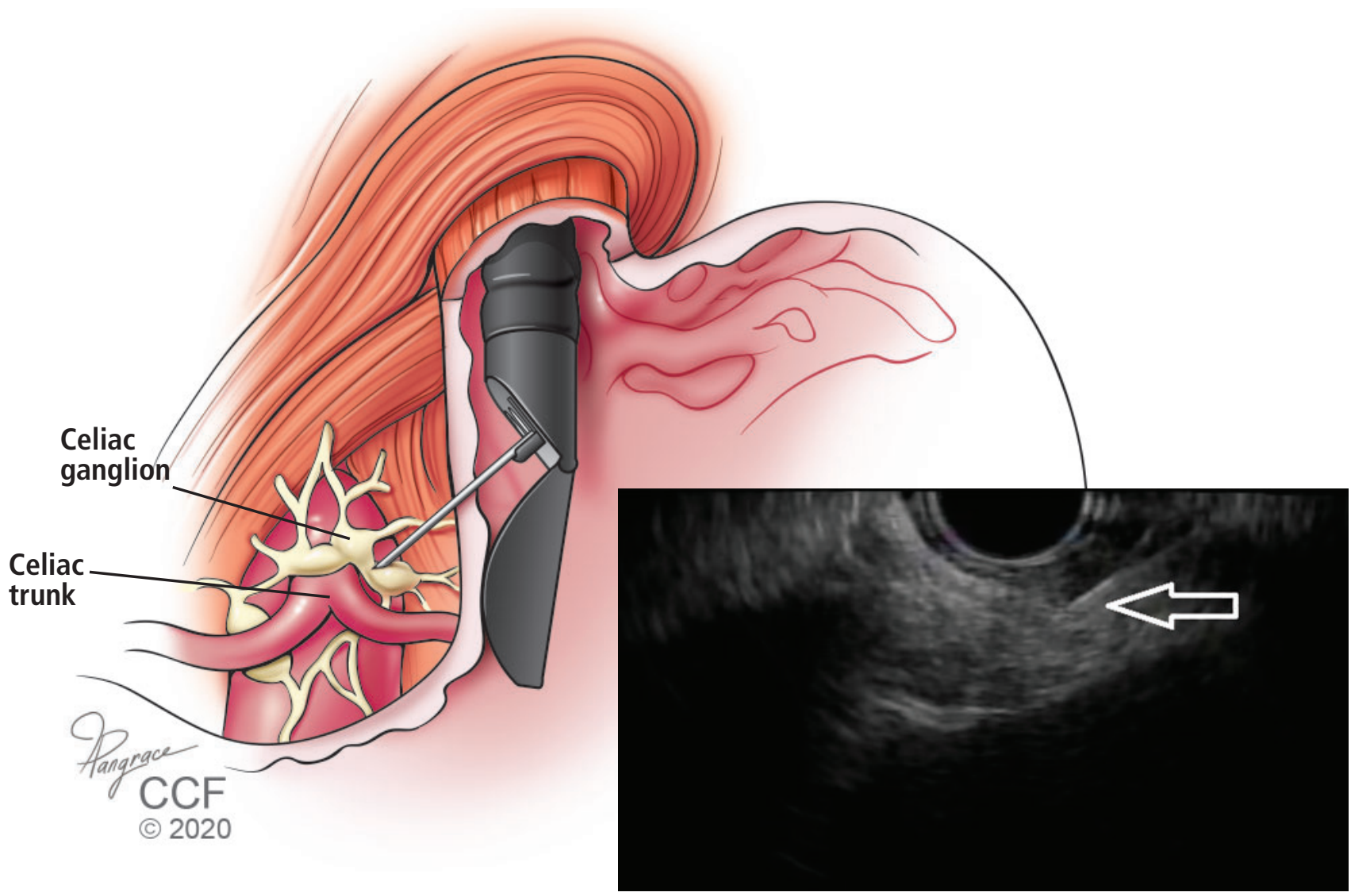

Figure 1. Control of chronic abdominal pain with first-line medications in patients with chronic pancreatitis or intra-abdominal malignancy may be inadequate or fraught with adverse effects. One alternative is endoscopic ultrasonography-guided fine-needle (EUS) celiac plexus block, performed under echoendoscopic guidance with passage of an injection needle. This procedure has been shown to be safe, is technically easy to perform, and is a safe alternative to percutaneous block guided by computed tomography. The arrow shows the EUS-guided placement of the needle.

\section{Cholecystitis}

Cholecystectomy is the optimal treatment for acute calculous or acalculous cholecystitis. $\mathrm{Pa}$ tients deemed high-risk surgical candidates cannot undergo the procedure and traditionally undergo percutaneous placement of a cholecystostomy tube by interventional radiology for decompression of the gallbladder. EUS can be used to perform transgastric or transduodenal gallbladder drainage with a covered metal stent. Case series have shown outcomes comparable to those of percutaneous tube placement. ${ }^{29,30}$

\section{GASTROINTESTINAL TRACT DISEASE}

\section{Upper tract conditions}

EUS can be used to identify benign tumors of the upper gastrointestinal tract, includ- ing submucosal esophagogastric tumors. ${ }^{31}$ EUS-guided fine-needle aspiration and biopsy can aid the cytohistologic diagnosis of esophagogastric solid subepithelial lesions. ${ }^{32}$

EUS is routinely used for diagnosis and staging of malignant esophageal tumors. The procedure may not be technically feasible if high-grade malignant esophageal stricture precludes passage of echoendoscope.

EUS-guided evaluation and biopsy are particularly useful to diagnose linitis plasti$\mathrm{ca}$, a gastric cancer characterized by marked thickening of deeper layers of gastric wall. It is difficult to diagnose with superficial mucosal biopsies rendered with esophagogastroduodenoscopy. 


\section{Mediastinal adenopathy}

\section{and non-small-cell lung cancer}

Nearly $26 \%$ of lung cancer patients present with mediastinal lymph node involvement. ${ }^{33}$ CT, MRI, and positron emission tomography are the common modalities for diagnosing mediastinal lymph node enlargement. However, lack of tissue sampling results only in a presumptive diagnosis. Posterior and inferior mediastinal lesions are especially suitable for EUS-guided fine-needle aspiration and biopsy for histologic diagnosis, thus avoiding an invasive surgical intervention like mediastinoscopy. However, EUS is unable to visualize anterior upper mediastinal nodes.

Mediastinal staging in lung cancer is an area in which EUS has made most significant impact. ${ }^{34}$ It also allows for evaluation of distant metastases involving adrenal glands.

\section{Submucosal lesions}

EUS provides a detailed image of gastrointestinal wall layers and therefore has become the principal tool for assessment of submucosal masses in this area.

Gastrointestinal stromal tumors are the most common mesenchymal tumors, and the stomach is the most common site. EUSguided fine-needle aspiration is considered the procedure of choice for preoperative diagnosis of these tumors, although it may provide inadequate material in one-third of cases. However, with the advent of newer biopsy needles, the histologic yield has improved significantly.

In addition to the diagnosis of gastrointestinal stromal tumors, EUS can distinguish between other benign lesions (leiomyoma, pancreatic rest, indolent neuroendocrine tumor, granular cell tumor, schwannoma, duplication cyst) and malignant lesions (primary or metastatic). EUS elastography is a promising technique that may also improve the distinction of benign from malignant lesions.

\section{Retroperitoneal masses}

For evaluation of idiopathic abdominal masses, EUS-guided fine-needle aspiration and biopsy provide a minimally invasive technique to obtain tissue samples for safe and accurate diagnosis, thus avoiding the need for exploratory laparotomy; it also helps guide subsequent therapy. ${ }^{35}$ These procedures are useful for evaluation of peri-intestinal and peri-esophageal lymph nodes and are more accurate than $\mathrm{CT}^{36}$

Apart from providing adequate diagnostic tissue in lymphoproliferative tumors, EUS is highly useful in nonpancreatic retroperitoneal masses such as adrenal metastasis, leiomyosarcoma, paraganglioma, and lymphangioma. EUS-associated seeding of the needle tract has been reported but is rare.

\section{Lower tract disease}

Accurate preoperative staging of rectal cancer leads to targeted treatment strategies, increased cure rates, and reduction in shortterm and long-term treatment failure. EUS and MRI have comparable accuracy in TNM staging of colorectal cancer, but MRI is perhaps more advantageous than EUS for nodal staging since it images the entire mesorectum.

\section{CELIAC PLEXUS BLOCK AND NEUROLYSIS}

Chronic abdominal pain is common and often disabling in patients with intra-abdominal malignancies and chronic pancreatitis. Pain relief from first-line medications including opiates may be inadequate or fraught with intolerances and adverse effects. ${ }^{37}$

Celiac plexus block with CT-guided percutaneous and EUS-guided neurolysis has been shown to be safe and technically easy to perform (Figure 1). In a Cochrane review of 6 randomized controlled trials with a total of 358 pancreatic cancer patients, ${ }^{38}$ the authors found that celiac plexus block with either approach caused fewer adverse effects than opioid analgesia. More study is needed to confirm a statistically significant improvement in pain scores.

\section{RECENT DEVELOPMENTS, NEWER INDICATIONS}

\section{EUS-guided fine-needle injection}

EUS-guided fine-needle injection is being evaluated for intratumoral chemotherapy in pancreatic and esophageal cancers. It has been used for tissue ablation by injection of ethanol in nonmalignant pancreatic cystic tumors and in radiofrequency ablation and brachytherapy in unresectable pancreatic cancers. Portal injection of chemotherapy has been shown to be safe and feasible. It may prove useful in the
EUS-guided gastrojejunostomy offers shorter recovery time than surgical gastrojejunostomy and is more cost-effective 
management of primary liver malignancies.

EUS-guided botulinum toxin injection for achalasia and for management of obesity has been done in few cases. Botox administration in the stomach promotes early satiety and weight loss through inhibition of acetylcholine-mediated peristalsis, ultimately delaying gastric emptying. ${ }^{39}$

\section{EUS-guided gastrojejunostomy}

Gastric outlet obstruction can result from malignancies involving stomach, duodenum, gallbladder, or pancreas. EUS-guided gastrojejunostomy has been reported to be a safe, durable, and successful treatment option..$^{40-42}$ Compared with enteral (duodenal) stenting, which can be complicated by tumor ingrowth resulting in stent occlusion, EUS-guided gastrojejunostomy has been shown to provide longer-lasting symptom relief since it is performed remotely from the tumor location. It also offers shorter recovery time and is more cost-effective than surgical gastrojejunostomy. ${ }^{43,44}$

\section{Contrast-enhanced harmonic EUS}

Contrast-enhanced harmonic EUS has been

DNA analysis

of specimens

obtained

by EUS-guided

fine-needle

aspiration

can aid

diagnosis developed to detect a microvascular pattern of lesions, which can help differentiate benign from malignant disease. An intravascular contrast agent is injected that contains microbubbles. On exposure to ultrasound, these microbubbles oscillate, and the transducer can make out the appearance of the peripheral microvasculature..$^{45}$

\section{Molecular marker analysis}

DNA analysis of specimens obtained by EUSguided fine-needle aspiration can aid diagnosis. Microdissection-based genotyping is now available at some centers. This has specific value in distinction of pancreatic cysts seen on CT. DNA quantification can help distinguish benign cysts from malignant ones.

\section{EUS-directed transgastric ERCP in patients with gastric bypass}

Duodenal and ampullary access with ERCP is difficult in patients who have undergone Roux-en-Y gastric bypass. Classically, enteroscopy-assisted ERCP is associated with a low success rate. Surgically assisted ERCP (laparoscopy or laparotomy) has a good success rate but is more invasive, has higher complication rates and longer length of stay in the hospital, with associated costs.

EUS-directed transgastric ERCP involves accessing the excluded stomach from the gastric pouch or Roux limb by creation of a fistula with placement of a removable lumen-apposing metal stent. Conventional ERCP can then be performed through the stent. A multicenter study comparing the EUS-directed procedure and laparoscopic ERCP found that the 2 procedures had similar success rates and adverse events. ${ }^{46}$ The EUS-directed procedure has the benefit of being an outpatient minimally invasive procedure with significantly shorter procedure time and cost. ${ }^{46,47}$

\section{Drainage of other nonpancreatic abdominopelvic fluid collections}

EUS is safe and effective in accessing and draining nonpancreatic abdominopelvic fluid collections from the stomach, duodenum, and colon. Multiple case series have reported safe and successful drainage of subphrenic abscesses, hepatic abscesses, bilomas, and pelvic and retroperitoneal abscesses. In addition, EUS has been increasingly utilized to drain postsurgical fluid collections, which can form anywhere in the abdominal cavity and can become symptomatic or infected. There is mounting recent evidence of successful EUS-guided drainage of such collections after common surgical procedures including Whipple surgery and Rouxen-Y gastric bypass. ${ }^{48}$

\section{EUS-guided angiotherapy}

EUS-guided angiotherapy is a relatively novel application that allows control of variceal bleeding by injecting coils and cyanoacrylate glue directly into the varices and confirming the thrombosis in real time with Doppler. It is purported that the combination of coil and glue might decrease the risk of glue embolization. However, further study is needed to establish the safety and superiority of this technique. ${ }^{34,49,50}$

\section{DRAWBACKS AND COMPLICATIONS}

Adverse events associated with sedation and standard endoscopic procedures are also applicable to EUS. However, since the echoendoscope has a larger diameter with a stiffer tip 
than the standard endoscope, it can be difficult to maneuver around the cricopharyngeus and duodenal bulb. It is also more time-consuming than standard routine endoscopy if fine-needle aspiration or intervention is planned. Despite this, complications, as reviewed below, are infrequent.

\section{Perforation}

Perforation is reported in the cervical esophagus and less often in the duodenum. The risk is usually similar to that with routine endoscopy $(0.03 \%)$. A prospective study of 4,894 patients undergoing upper EUS found a cervical esophageal perforation rate of $0.06 \%$ (3 patients, with a curved linear array endoscope). ${ }^{51} \mathrm{~A}$ recent systematic review reported a perforation rate of $0.02 \%$ with EUS. ${ }^{52}$ The risks may be higher in patients with strictures, malignancy, older age, or history of difficult intubation, and with a less experienced operator.

\section{Infection}

The risk of bacteremia after EUS-guided fineneedle aspiration is lower than with diagnostic endoscopy, and prophylactic antibiotics are not recommended for aspiration of solid masses and lymph nodes. ${ }^{53,54}$ Some experts recommend prophylactic antibiotics as well as
48 hours of antibiotics after fine-needle aspiration of the perirectal space..$^{55}$

EUS-guided aspiration of cystic lesions may carry an increased risk of febrile episodes and possibly sepsis. Therefore, prophylactic antibiotics followed by a short postprocedure course has been recommended..$^{56}$

There have been isolated reports of streptococcal sepsis, mediastinitis, retroperitoneal abscess, perirectal abscess, and cholangitis. ${ }^{57}$

\section{Pancreatitis}

EUS-guided fine-needle aspiration of pancreatic lesions involves direct passage of the needle through pancreatic tissue. Reported rates of pancreatitis associated with this procedure range from $0 \%$ to $2 \% .{ }^{58} \mathrm{~A}$ recent meta-analysis of 51 studies found a rate of of $0.44 \% .{ }^{59}$

\section{Hemorrhage}

A recent meta-analysis of related adverse events reported a bleeding rate of $0.13 \% .{ }^{59}$

\section{Avoiding complications}

Careful patient selection, familiarity with the equipment, and planning of the procedure are keys to avoiding complications. Early recognition of complications and prompt intervention can reduce morbidity and mortality risk.

\section{REFERENCES}

1. Williams DB, Sahai AV, Aabakken L, et al. Endoscopic ultrasound guided fine needle aspiration biopsy: a large single centre experience. Gut 1999; 44(5):720-726. doi:10.1136/gut.44.5.720

2. ASGE Standards of Practice Committee; Maple JT, Ben-Menachem T, Anderson MA, et al. The role of endoscopy in the evaluation of suspected choledocholithiasis. Gastrointest Endosc 2010; 71(1):1-9. doi:10.1016/j.gie.2009.09.041

3. Mekky MA, Yamao K, Sawaki A, et al. Diagnostic utility of EUSguided FNA in patients with gastric submucosal tumors. Gastrointest Endosc 2010; 71(6):913-919. doi:10.1016/j.gie.2009.11.044

4. Akahoshi K, Chijiiwa Y, Nakano l, et al. Diagnosis and staging of pancreatic cancer by endoscopic ultrasound. Br J Radiol 1998; 71(845):492-496. doi:10.1259/bjr.71.845.9691893

5. Gonzalo-Marin J, Vila JJ, Perez-Miranda M. Role of endoscopic ultrasound in the diagnosis of pancreatic cancer. World J Gastrointest Oncol 2014; 6(9):360-368. doi:10.4251/wjgo.v6.i9.360

6. Müller MF, Meyenberger C, Bertschinger P, Schaer R, Marincek B. Pancreatic tumors: evaluation with endoscopic US, CT, and MR imaging. Radiology 1994; 190(3):745-751. doi:10.1148/radiology.190.3.8115622

7. Ridtitid W, Schmidt SE, Al-Haddad MA, et al. Performance characteristics of EUS for locoregional evaluation of ampullary lesions. Gastrointest Endosc 2015; 81(2):380-388. doi:10.1016/j.gie.2014.08.005

8. Bhattacharya A, Cruise M, Chahal P. Endoscopic ultrasound guided 22 gauge core needle biopsy for the diagnosis of autoimmune pancreatitis. Pancreatology 2018; 18(2):168-169. doi:10.1016/j.pan.2018.01.003

9. Banks PA, Bollen TL, Dervenis C, et al; Acute Pancreatitis Classifica- tion Working Group. Classification of acute pancreatitis-2012: revision of the Atlanta classification and definitions by international consensus. Gut 2013; 62(1):102-111. doi:10.1136/gutjnl-2012-302779

10. Park DH, Lee SS, Moon SH, et al. Endoscopic ultrasound-guided versus conventional transmural drainage for pancreatic pseudocysts: a prospective randomized trial. Endoscopy 2009; 41(10):842-848. doi:10.1055/s-0029-1215133

11. Lu X, Zhang S, Ma C, Peng C, Lv Y, Zou X. The diagnostic value of EUS in pancreatic cystic neoplasms compared with CT and MRI. Endosc Ultrasound 2015; 4(4):324-329. doi:10.4103/2303-9027.170425

12. Varadarajulu S, Christein JD, Tamhane A, Drelichman ER, Wilcox CM. Prospective randomized trial comparing EUS and EGD for transmural drainage of pancreatic pseudocysts (with videos). Gastrointest Endosc 2008; 68(6):1102-1111. doi:10.1016/j.gie.2008.04.028

13. Chong AK, Hawes R, Hoffman B, et al. Diagnostic performance of endoscopic ultrasound for chronic pancreatitis: a comparison with histopathology. Gastrointest Endosc 2007; 65(6):808-814. doi:10.1016/j.gie.2006.09.026

14. Schmitz-Moormann P, Himmelmann GW, Brandes JW, et al. Comparative radiological and morphological study of human pancreas. Pancreatitis like changes in post mortem ductograms and their morphological pattern. Possible implication for ERCP. Gut 1985; 26(4):406-414. doi:10.1136/gut.26.4.406

15. Malfertheiner $P$, Buchler M, Stanescu A, Ditschuneit $H$. Exocrine pancreatic function in correlation to ductal and parenchymal morphology in chronic pancreatitis. Hepatogastroenterology 1986; 33(3):110-114. pmid:3744281

16. Heij HA, Obertop H, van Blankenstein M, et al. Comparison of endoscopic retrograde pancreatography with functional and histologic changes in chronic pancreatitis. Acta Radiol 1987; 28(3):289-293. 
pmid:2958034

17. Buxbaum J, Ko C, Varghese N, et al. Qualitative and quantitative contrast-enhanced endoscopic ultrasound improves evaluation of focal pancreatic lesions. Clin Gastroenterol Hepatol 2019:S15423565(19)30976-0. doi:10.1016/j.cgh.2019.08.054 [Epub ahead of print]

18. Harmsen F-JR, Domagk D, Dietrich CF, Hocke M. Discriminating chronic pancreatitis from pancreatic cancer: contrast-enhanced EUS and multidetector computed tomography in direct comparison. Endosc Ultrasound 2018; 7(6):395-403. doi:10.4103/eus.eus_24_18

19. Scheiman JM, Hwang JH, Moayyedi P. American Gastroenterological Association technical review on the diagnosis and management of asymptomatic neoplastic pancreatic cysts. Gastroenterology 2015 148(4):824-848.e22. doi:10.1053/j.gastro.2015.01.014

20. Gress F, Gottlieb K, Cummings O, Sherman S, Lehman G. Endoscopic ultrasound characteristics of mucinous cystic neoplasms of the pancreas. Am J Gastroenterol 2000; 95(4):961-965. doi:10.1111/j.1572-0241.2000.01976.x

21. Tanaka M, Chari S, Adsay V, et al; International Association of Pancreatology. International consensus guidelines for management of intraductal papillary mucinous neoplasms and mucinous cystic neoplasms of the pancreas. Pancreatology 2006; 6(1-2):17-32. doi:10.1159/000090023

22. Tanaka M, Fernández-Del Castillo C, Kamisawa T3, et al. Revisions of international consensus Fukuoka guidelines for the management of IPMN of the pancreas. Pancreatology 2017; 17(5):738-753. doi:10.1016/j.pan.2017.07.007

23. Reinhold C, Taourel P, Bret PM, et al. Choledocholithiasis: evaluation of MR cholangiography for diagnosis. Radiology 1998; 209(2):435442. doi:10.1148/radiology.209.2.9807570

24. Guibaud L, Bret PM, Reinhold C, Atri M, Barkun AN. Diagnosis of choledocholithiasis: value of MR cholangiography. AJR Am J Roentgenol 1994; 163(4):847-850. doi:10.2214/ajr.163.4.8092021

25. Regan F, Fradin J, Khazan R, Bohlman M, Magnuson T. Choledocholithiasis: evaluation with MR cholangiography. AJR Am J Roentgenol 1996; 167(6):1441-1445. doi:10.2214/ajr.167.6.8956574

26. Becker CD, Grossholz M, Becker M, Mentha G, de Peyer R, Terrier F. Choledocholithiasis and bile duct stenosis: diagnostic accuracy of MR cholangiopancreatography. Radiology 1997; 205(2):523-530. doi:10.1148/radiology.205.2.9356639

27. Hathorn KE, Bazarbashi AN, Sack JS, et al. EUS-guided biliary drainage is equivalent to ERCP for primary treatment of malignant distal biliary obstruction: a systematic review and meta-analysis. Endosc Int Open 2019; 7(11):E1432-E1441. doi:10.1055/a-0990-9488

28. Mohan BP, Shakhatreh M, Garg R, Ponnada S, Navaneethan U, Adler DG. Efficacy and safety of endoscopic ultrasound-guided choledochoduodenostomy: a systematic review and meta-analysis. J Clin Gastroenterol 2019; 53(4):243-250. doi:10.1097/MCG.0000000000001167

29. Baron TH, Topazian MD. Endoscopic transduodenal drainage of the gallbladder: implications for endoluminal treatment of gallbladder disease. Gastrointest Endosc 2007; 65(4):735-737. doi:10.1016/j.gie.2006.07.041

30. Choi JH, Kim HW, Lee JC, et al. Percutaneous transhepatic versus EUS-guided gallbladder drainage for malignant cystic duct obstruction. Gastrointest Endosc 2017; 85(2):357-364. doi:10.1016/j.gie.2016.07.067

31. Debol SM, Stanley MW, Mallery S, Sawinski E, Bardales RH. Glomus tumor of the stomach: cytologic diagnosis by endoscopic ultrasound-guided fine-needle aspiration. Diagn Cytopathol 2003; 28(6):316-321. doi:10.1002/dc.10294

32. Akahoshi K, Oya M, Koga T, et al. Clinical usefulness of endoscopic ultrasound-guided fine needle aspiration for gastric subepithelial lesions smaller than $2 \mathrm{~cm}$. J Gastrointestin Liver Dis 2014; 23(4):405412. doi:10.15403/jgld.2014.1121.234.eug

33. Silvestri GA, Gonzales AV, Jantz MA, et al. Methods of staging non-small cell lung cancer: diagnosis and management of lung cancer, 3rd ed: American College of Chest Physicians Evidence-Based Clinical Practice Guidelines. Chest 2013; 143(5 suppl):e211S-e250S. doi:10.1378/chest.12-2355

34. Redondo-Cerezo E, Martínez-Cara JG, Esquivias J, et al. Endoscopic ultrasonography-fine needle aspiration versus PET-CT in undiagnosed mediastinal and upper abdominal lymphadenopathy: a comparative clinical study. Eur J Gastroenterol Hepatol 2015; 27(4):455-459. doi:10.1097/MEG.0000000000000302

35. Catalano MF, Sial S, Chak A, et al. EUS-guided fine needle aspiration of idiopathic abdominal masses. Gastrointest Endosc 2002; 55(7):854-858. doi:10.1067/mge.2002.122956

36. Findlay JM, Bradley KM, Maile EJ, et al. Pragmatic staging of oesophageal cancer using decision theory involving selective endoscopic ultrasonography, PET and laparoscopy. Br J Surg 2015; 102(12):1488-1499. doi:10.1002/bjs.9905

37. Wyse JM, Carone M, Paquin SC, Usatii M, Sahai AV. Randomized, double-blind, controlled trial of early endoscopic ultrasound-guided celiac plexus neurolysis to prevent pain progression in patients with newly diagnosed, painful, inoperable pancreatic cancer. J Clin Oncol 2011; 29(26):3541-3546. doi:10.1200/JCO.2010.32.2750

38. Arcidiacono PG, Calori G, Carrara S, McNicol ED, Testoni PA. Celiac plexus block for pancreatic cancer pain in adults. Cochrane Data Base Syst Rev 2011; 3:CD007519. doi:10.1002/14651858.CD007519.pub2

39. de Moura EGH, Ribeiro IB, Frazão MSV, et al. EUS-guided intragastric injection of botulinum toxin $A$ in the preoperative treatment of super-obese patients: a randomized clinical trial. Obes Surg 2019; 29(1):32-39. doi:10.1007/s11695-018-3470-y

40. Khashab MA, Baron TH, Binmoeller KF, Itoi T. EUS-guided gastroenterostomy: a new promising technique in evolution. Gastrointest Endosc 2015; 81(5):1234-1236. doi:10.1016/j.gie.2014.12.053

41. Ikeuchi N, Itoi T, Tsuchiya T, Nagakawa Y, Tsuchida A. One-step EUS guided gastrojejunostomy with use of lumen-apposing metal stent for afferent loop syndrome treatment. Gastrointest Endosc 2015; 82(1):166. doi:10.1016/j.gie.2015.01.010

42. Itoi T, Ishii K, Tanaka R, Umeda J, Tonozuka R. Current status and perspective of endoscopic ultrasonography-guided gastrojejunostomy: endoscopic ultrasonography-guided double-balloon-occluded gastrojejunostomy (with videos). J Hepatobiliary Pancreat Sci 2015; 22(1):3-11. doi:10.1002/jhbp.148

43. Urrehman A, Khor CJ, Ka CY, Asokkumar R, Tan D. Su1449 EUSguided gastrojejunostomy using a lumen apposing metal stent in patients with symptomatic gastric outlet obstruction. Gastrointestinal Endoscopy 2018; 87(6):AB359. doi:10.1016/j.gie.2018.04.1779

44. Perez-Miranda M, Tyberg A, Poletto D, et al. EUS-guided gastrojejunostomy versus laparoscopic gastrojejunostomy: an international collaborative study. J Clin Gastroenterol 2017; 51(10):896-899. doi:10.1097/MCG.0000000000000887

45. Iglesias-Garcia J, Lindkvist B, Cruz-Soares JB, Larino-Noia J, Dominguez-Munoz E. SA1208 Does contrast enhancement play a role as an adjunct to endoscopic ultrasound for the diagnosis of chronic pancreatitis? A pilot study. Gastroenterology 2012; 142(5, suppl 1): S243-S244.

46. Kedia P, Sharaiha RZ, Kumta NA, Kahaleh M. Internal EUS-directed transgastric ERCP (EDGE): game over. Gastroenterology 2014; 147(3):566-568. doi:10.1053/j.gastro.2014.05.045

47. Kedia P, Tarnasky PR, Nieto J, et al. EUS-directed transgastric ERCP (EDGE) versus laparoscopy-assisted ERCP (LA-ERCP) for Roux-en-Y gastric bypass (RYGB) anatomy: a multicenter early comparative experience of clinical outcomes. J Clin Gastroenterol 2019; 53(4):304308. doi:10.1097/MCG.0000000000001037

48. Simons-Linares CR, Rodriguez J, Chahal P. EUS-guided drainage of post-operative subphrenic fluid collection through gastric pouch with a lumen-apposing metal stent in a patient with Roux-en-Y gastric bypass. Obes Surg 2018; 28(10):3301-3303. doi:10.1007/s11695-018-3422-6

49. Mouri R, Yoshida S, Tanaka S, Oka S, Yoshihara M, Chayama K. Usefulness of endoscopic ultrasonography in determining the depth of invasion and indication for endoscopic treatment of early gastric cancer. J Clin Gastroenterol 2009; 43(4):318-322. doi:10.1097/MCG.0b013e3181775966 


\section{SIMONS-LINARES AND COLLEAGUES}

50. Fujii-Lau LL, Levy MJ. EUS-guided angiotherapy: a sticky situation. Gastrointest Endosc 2016; 83(6):1173-1175. doi:10.1016/j.gie.2015.12.015

51. Eloubeidi MA, Tamhane A, Lopes TL, Morgan DE, Cerfolio RJ. Cervical esophageal perforations at the time of endoscopic ultrasound: a prospective evaluation of frequency, outcomes, and patient management. Am J Gastroenterol 2009; 104(1):53-56. doi:10.1038/ajg.2008.21

52. Wang KX, Ben QW, Jin ZD, et al. Assessment of morbidity and mortality associated with EUS-guided FNA: a systematic review. Gastrointest Endosc 2011; 73(2):283-290. doi:10.1016/j.gie.2010.10.045

53. Touchefeu Y, Le Rhun M, Coron E, et al. Endoscopic ultrasound-guided fine-needle aspiration for the diagnosis of solid pancreatic masses: the impact on patient-management strategy. Aliment Pharmacol Ther 2009; 30(10):1070-1077. doi:10.1111/j.1365-2036.2009.04138.x

54. Wilson JL, Kalade A, Prasad S, et al. Diagnosis of solid pancreatic masses by endoscopic ultrasound-guided fine-needle aspiration. Intern Med J 2009; 39(1):32-37. doi:10.1111/j.1445-5994.2008.01633.x

55. Hirota WK, Petersen K, Baron TH, et al; Standards of Practice Committee of the American Society for Gastrointestinal Endoscopy. Guidelines for antibiotic prophylaxis for GI endoscopy. Gastrointest
Endosc 2003; 58(4):475-482. doi:10.1067/s0016-5107(03)01883-2

56. Ryan AG, Zamvar V, Roberts SA. latrogenic candidal infection of a mediastinal foregut cyst following endoscopic ultrasoundguided fine-needle aspiration. Endoscopy 2002; 34(10):838-839. doi:10.1055/s-2002-34262

57. Gress F, Schmitt C, Sherman S, Ciaccia D, Ikenberry S, Lehman G Endoscopic ultrasound-guided celiac plexus block for managing abdominal pain associated with chronic pancreatitis: a prospective single center experience. Am J Gastroenterol 2001; 96(2):409-416. doi:10.1111/j.1572-0241.2001.03551.x

58. Gress F, Michael H, Gelrud D, et al. EUS-guided fine-needle aspiration of the pancreas: evaluation of pancreatitis as a complication. Gastrointest Endosc 2002; 56(6):864-867. doi:10.1067/mge.2002.129602

59. Wang KX, Ben QW, Jin ZD, et al. Assessment of morbidity and mortality associated with EUS-guided FNA: a systematic review. Gastrointest Endosc 2011; 73(2):283-290. doi:10.1016/j.gie.2010.10.045

Address: Prabhleen Chahal, MD, Department of Gastroenterology, Hepatology, and Nutrition, A31, Cleveland Clinic, 9500 Euclid Avenue, Cleveland, OH 44195; chahalp@ccf.org 